\title{
A 10-year retrospective descriptive study of internists' complaints referred to Fars Legal Medicine Center
}

\author{
Pedram Keshavarz ${ }^{1}$, Mehdi Dehghani ${ }^{2,5^{*}}$, Fatemeh Malekpour ${ }^{3}$, Saeid Gholamzadeh4, \\ Mohammad Zarenezhad ${ }^{4}$ and Abdorrasoul Malekpour ${ }^{4}$
}

\begin{abstract}
The high rate of medical errors, malpractice payments, legal issues, and complaints from physicians leads to waste of the physician's time and energy as well as high costs for related individuals and organizations.

Patients and methods: We analyzed the outcomes of 275 medical malpractice cases reported in the Department of Forensic Medicine in Fars Province from January 2006 to December 2016. The study population included all the internists as defendants and the patients who had filed a complaint against them.

Results: Based on the plaintiffs' gender in the investigated cases, the maximum age of patients with complaints by gender among males ranged between 30-39 and 50-59 years (22.4\%) and among females it was 30-39 years (22. 8\%). The degrees of physicians who had been accused of medical commission were recognized as follows: 5 (1.8\%) medical students, 36 (13.1\%) GPs (general practitioners), 126 (45.8\%) internists, 6 (2.2\%) pulmonologists, 6 (2.2\%) nephrologists, 4 (1.5\%) hematologists, 2 (0.7\%) rheumatologists, and 38 (13.9\%) gastroenterologists.

Conclusions: Annual malpractice from the beginning of 2006 to the end of 2016 varied from 0 to 5\%, while the rate of annual complaints in the same period varied from 0 to $45 \%$. Maximum malpractice payment belonged to gynecology which is about $50,358,000$ Rials equivalent to US\$11,990 involving malpractice and complaint concurrent with internists. Specially fields of general surgery(9.4\%), gynecology (9.1\%), subspecialty fields of thoracic cardiovascular surgery (6.9\%), and family general practice (13.1\%) were the fields of most complaints parallel with those of internists.
\end{abstract}

Keywords: Forensic medicine, Complain, Internist, Medical errors, Malpractice payment

\section{Background}

Today, physician's malpractice in Iran has been increased due to economic slump and financial problems and reduced people's general incomes. Therefore, many people want to compensate these property damages and lack of finance with complaints from physicians. One of the most important occupational challenges of physicians is patients' discontent and complaints (Zengin et al., 2014) which are referred to a forensic medicine center and also its sequences in patients' lives which may take place

\footnotetext{
* Correspondence: mehdi_dehghani6@yahoo.com

${ }^{2}$ Hematology Research Center, Hematology and Medical Oncology

Department, Shiraz University of Medical Sciences, Shiraz, Iran

5 Internal Medicine Department, Namazee Hospital, P.O. Box: 7194835356 ,

Zand Street, Shiraz, Iran

Full list of author information is available at the end of the article
}

everywhere in the health care systems (Velsor et al., 2018; Obama, 2016). Health care systems are defined through dependence on human operators who work with uncertainty, complicated cumulative technology, and different kinds of facilities (Mossialos et al., 2016). Errors and legal issues are inevitable and may have serious effects on patients' lives (Popescu, 2015). These sequences not only waste the physician's time and energy (Oshel \& Levitt, 2016) but also are a stressing situation that any physician with any academic degree and expertise may face during her/his professional life (Castro et al., 2018).

Medical malpractice includes diagnosis, misdiagnosis, and treatment of diseases. Namely, malpractice can occur in the first referral of a patient to a doctor or it can occur during management and treatment of a patient's 
problem or disease (Gaither \& Copp, 2016). In other words, malpractice is a failure and lack of competence and knowledge of physicians in the diagnosis and treatment in a standard level (Jimenez-Corona et al., 2006). Medical malpractice includes different types as lack of skill, lack of respect to the governmental system, imprudence, and inconsiderateness. Lack of skill can result from being amateur and inexperienced, or insufficient boon from medical knowledge and updated medical sciences (Traina, 2009). Lack of respect to the governmental system means disregarding of established rules by the ministry of health and/ or health deputy which can occur due to negligence or incompetence (King \& Crewe, 2014). Imprudence is defined as giving up an action due to negligence, delinquency, and forgetfulness (Hamilton, 2016). In fact, it means that a person has done something that should not be done (Arhan et al., 2009). Inconsiderateness means lack of awareness of a physician of an obligation which he/she did not perform (Nakanishi, 2014). In the case of an error, patients tend to learn about a medical error if it happens or they want to know the cause of complication, and acquire ways to prevent its recurrence (Madea \& Preuß, 2009).

Nowadays, the rate of dissatisfaction and complaints of the patients is increasing despite physicians and therapeutic staff's efforts and use of available facilities (Friele et al., 2015). According to the statistics of the USA, in 1970, 3 to $4 \%$ complaints were recorded against physicians. In 1980 , this rate increased to $20 \%$, and in the year 1990, it reached to 25\% (Dyrbye \& Shanafelt, 2016; Kermode-Scott, 2005). Also, 11 states of the USA show that the data of medical malpractices since 1993 to 2002 increased by $18 \%$. In Italy, the hospitals were against claims of medical malpractice beside physicians in offices. Yet, the number of confirmed cases has been declared about mistreatments of physicians in private offices more than those working in hospitals specially for esthetic medicine (Dyrbye \& Shanafelt, 2016). In most cases, autopsy proves that medical malpractice has not taken place and also there is no real scientific connection between the suspect misuse and the patient death (Casali et al., 2014).

Malpractice in Iran has increased as economic condition has worsened and economic and financial sanctions have been imposed against the government by other countries. On the other hand, in Iran there are not widespread studies in the case of internal medical malpractice field, so this study aimed to estimate the magnitude of the internal malpractice field and its five related subspecialties and also other fields' specialists that receive complaints simultaneously.

\section{Patients and methods}

\section{Study sites}

We analyzed the outcomes of 275 medical malpractice cases reported in the Department of Forensic Medicine in
Fars Province between January 2006 and December 2016. Inclusion criteria in this study were all the internists as defendants, patients who had filed a complaint against them, and all cases that reached a definite result at this interval. Cases which had not yet been resolved or had not yet been issued at this period were excluded from this study.

This research was designed to be a retrospective descriptive case study, focusing on cases like the type of malpractice, the percentage and amount of malpractice paid damage, the type of initial reference of the plaintiff to the health center, and the place of death. Data were classified into six categories based on the specialties and subspecialties: internist, gastroenterology, nephrology, endocrinology, rheumatology, oncology, and other specialties and physicians against whom there were complaints simultaneously with internists.

Demographic characteristics of patients, including sex, age, and educational level, were recorded. Then, the main cause of the claims and the type of the defect were tabulated. Types of medical malpractice were classified as follows: (1) inconsiderateness, (2) imprudence, (3) lack of skill, and (4) lack of respect to the governmental system due to negligence or incompetence (Beigi et al., 2015).

\section{Statistical analysis}

Collected data were analyzed in SPSS software version 19.0. Figures and tables were used to express the descriptive results. Data were presented as mean \pm standard deviation (SD) and frequencies as percentages (\%).

\section{Ethics}

Human dignity, confidentiality of individuals' information, and also commitment to Helsinki Ethics have been respected throughout the study. The executive protocol of this study was confirmed by the ethics committee of Shiraz University of Medical Sciences, and investigation of the cases was conducted at Fars Forensic Medicine due to the confidentiality of the cases; also, the secrecy tenet was respected throughout the study.

\section{Results}

Based on the plaintiffs' sexuality in the investigated cases, the frequency of male plaintiffs was 147 cases (53.4\%) and female plaintiffs was 127 cases (46.1\%); in 1 case $(0.3 \%)$, sex was not recorded. Maximum age range of the patients with complaints by sex in males was 30 39 and $50-59$ years $(n=23,11.25 \%)$ and in females it was $30-39$ years (11.45\%) (Fig. 1).

Among the 275 cases of the complaints against internists and aforementioned subspecialists, minimum cases and commissions belonged to the year $2007(n=5,1.8 \%)$ and maximum commissions of complaints belonged to the year 2014 ( $n=114,41.5 \%)$ (Fig. 2). Also, the maximum 


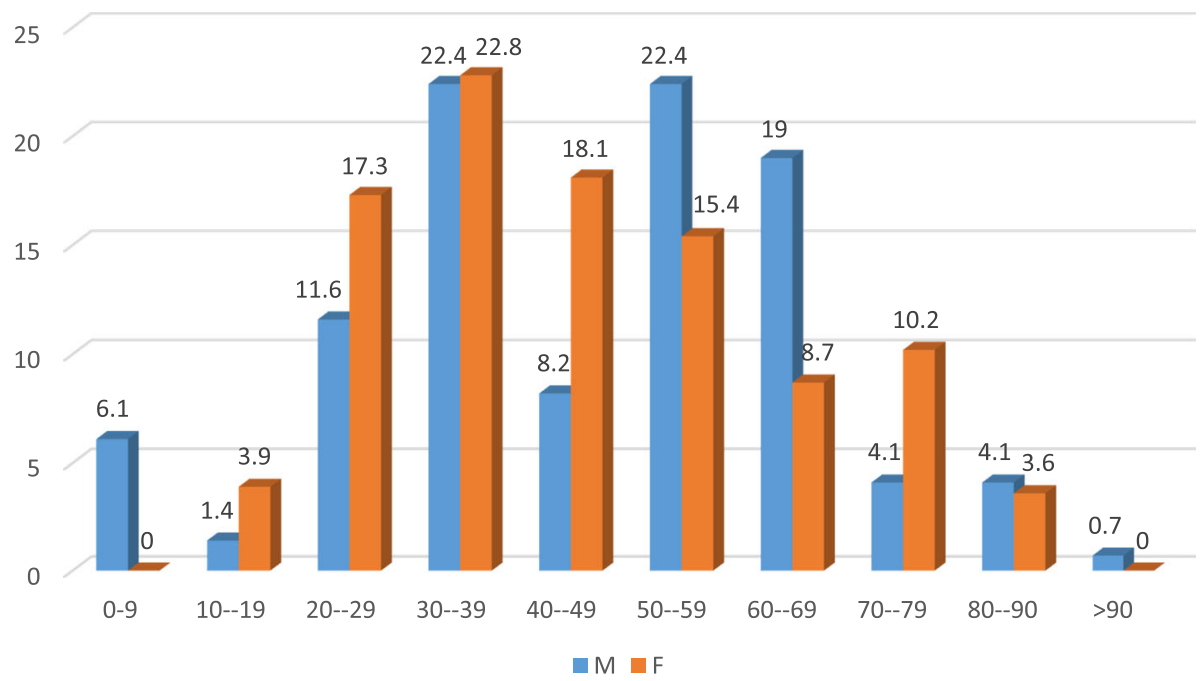

Fig. 1 Frequency distribution of the plaintiffs in complaints based on the plaintiffs' sex and age range into percentage

age range of complaints in male was more than 90 years which was one person $(0.7 \%)$ and there was no similar case in females (Fig. 2). The frequency of the plaintiffs' education was as follows: 29 cases (11\%) illiterate, 73 cases (27\%) elementary school, 55 cases (20\%) middle school, 44 cases (16\%) diploma, 23 cases (8\%) associate degree, 27 cases $(10 \%)$ bachelor, 4 cases (1\%) master's degree, 9 cases (3\%) doctorate, and in 11 cases, the plaintiffs' education was not recorded. Among these 275 cases, 64 cases (23\%) were single and 210 cases (76\%) were married, and in 1 case, the marital status was not recorded.

Among the 275 investigated cases, the situation of the plaintiff which occurred after malpractice (according to their first referral for their compliant) included the following: 189 cases (68.7\%) death, 39 (14.2\%) malformation, 42 $(15.3 \%)$ recovering, and 4 cases $(1.8 \%)$ recovered.

Frequency distribution and type of plaintiff's primary reference to the therapeutic center according to the situation of the plaintiff were as follows: 249 cases of all cases (90.5\%) emergency approach, 16 cases (5.8\%) outpatient approach, and 10 cases (3.6\%) active or selective approach (Table 1). In the investigation of 275 cases, the types of malpractice were recognized as follows: 163 cases (59.3\%) of inconsiderateness, 37 cases (13.5\%) of imprudence, 50 cases $(18.2 \%)$ of lack of skill, 19 cases (6.9\%) of lack of respect to the governmental system, and in 6 cases $(2.2 \%)$, and 2 types of malpractice happened simultaneously.

Based on 275 cases of the malpractice, the frequency of different types of specialty and academic degree of physicians who were complained about in the medical commission were recognized as follows: $5(1.8 \%)$ medical interns, 36 (13.1\%) GPs (general practitioner), 126 (45.8\%) internists, 6 (2.2\%) pulmonologists, 6 (2.2\%) nephrologists, 4 (1.5\%) hematologists, 2 (0.7\%) rheumatologists, and $38(13.9 \%)$ gastroenterologists. Specialty

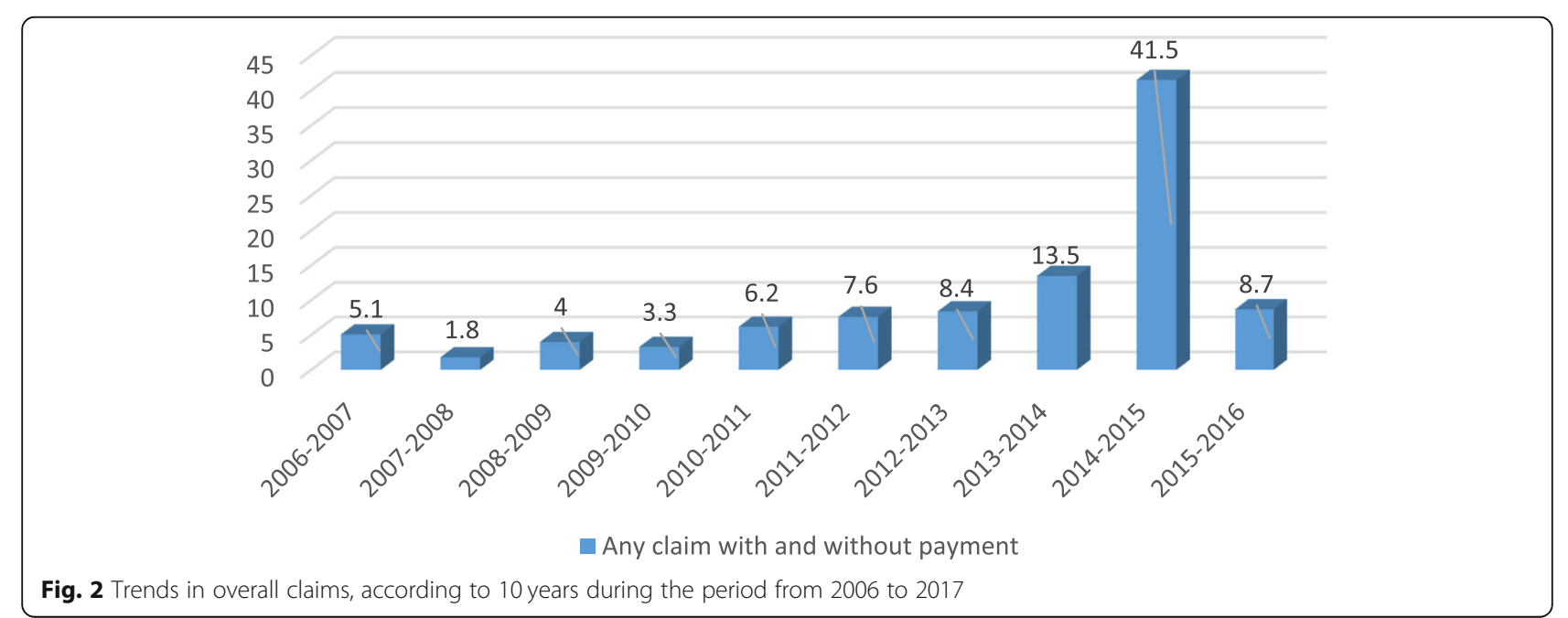


Table 1 Frequency distribution and type of plaintiff's primary reference to the therapeutic center according to the situation of the plaintiff

\begin{tabular}{lllll}
\hline & EMS & Outpatient & Active $^{*}$ & Total \\
\hline Death & $183(66.5 \%)$ & $3(1.1 \%)$ & $3(1.1 \%)$ & $189(68.7 \%)$ \\
Malformation & $30(10.9 \%)$ & $6(2.2 \%)$ & $3(1.1 \%)$ & $39(14.2 \%)$ \\
Recovering & $31(11.3 \%)$ & $7(2.5 \%)$ & $4(1.5 \%)$ & $42(15.3 \%)$ \\
Recovered & $5(1.8 \%)$ & $0(0.0 \%)$ & $0(0.0 \%)$ & $5(1.8 \%)$ \\
Total & $249(90.5 \%)$ & $16(5.8 \%)$ & $10(3.6 \%)$ & $275(100.0 \%)$
\end{tabular}

*Active means patient's selective approach

EMS emergency medical service

fields of general surgery (9.4\%) and gynecology (9.1\%) and subspecialty fields of thoracic cardiovascular surgery (6.9\%) and family general practice (13.1\%) were the fields that had been most complained about simultaneously with internal medicine. Most cases accused of malpractice were family general practitioners that were complained against simultaneously with internists (Table 2). Among 275 suspects, 163 cases (59.2\%) were acquittal and 112 cases (40\%) convicted of malpractice in the treatment in the final judgment.

\section{Discussion}

The high rate of medical errors, malpractice payments, legal issues, and complaints from physicians leads to waste of the physician's time and energy as well as high costs for related individuals and organizations. With respect to sex among males (53.4\%) and females (46.6\%), there were no significant differences in the number of the complaints. The most common level of the plaintiffs' education was elementary (27\%) and the least common level belonged to master's degree (1\%); based on statistical tests, it can be concluded that there was a significant relationship between education and the number of complaints, in such a way that education affects reduction in the number of complaints and we did not find any study with a similar education level. The most frequent complaints were in the year $2014(41.5 \%)$ and the least frequent ones happened in the year 2007 (1.8\%). This result is very similar to other studies conducted in Asia such as those of Li et al. and Buken et al. in China and Turkey, and interestingly in Iran, the ascending trend of complaints against physicians is visible ( $\mathrm{Li}$ et al., 2017; Büken et al., 2004).

In this study and based on the investigations, educational and public medical centers were at the top in the rate of complaints and this can be due to the old educational curriculum and also lack of medical equipment and facilities. The reason of hospitalization made a significant difference in the number of complaints as the emergency medicine service section dominated $90 \%$ of complaints and the most malpractice by physician occurred due to inconsiderateness and negligence (59\%), similar to the results of Beigi et al. in Isfahan (Beigi et al., 2015).

Annual malpractice from the beginning of 2006 to the end of 2016 varied between 0 and 5\% generally, while the rate of the annual complaints in the same period varied between 0 and $45 \%$, in which in contrast to the results of Studdert et al.'s study in USA (Studdert et al., 2006). This rate indicates that the complaints of patients against physicians and therapeutic staff are ascending annually, but the percentage of physician accusations and also paid malpractice payment amount have not significantly increased (Schaffer et al., 2017) (Fig. 3). This result indicates that the most common reason of complaints against physicians during this period is the increasing rate of economic slump and financial problems in Iran which put people under pressure, so finally, people need to meet their needs in other ways such as these complaints.

Table 2 Frequency distribution percentage of the plaintiffs' side effect and death according to the type of side effect and death

\begin{tabular}{|c|c|c|}
\hline & Cause of death & Total frequency \\
\hline \multirow[t]{7}{*}{ Death } & After CABG & $6.1 \%$ \\
\hline & PTE and lung emboli & $8.3 \%$ \\
\hline & Gl bleeding after colonoscopy, endoscopy, and ERCP & $13.8 \%$ \\
\hline & Kidney failure & $5.4 \%$ \\
\hline & Miss diagnosis & $9 \%$ \\
\hline & Wrong type blood transfusion & $1.4 \%$ \\
\hline & Others & $16.9 \%$ \\
\hline \multirow[t]{5}{*}{ Side effects } & Internal bleeding after surgery & $4.3 \%$ \\
\hline & Acute kidney injury & $3.6 \%$ \\
\hline & Sepsis after hospital admission & $12.3 \%$ \\
\hline & Gl perforation after colonoscopy, endoscopy, and ERCP & 10.5 \\
\hline & Others & $8.4 \%$ \\
\hline
\end{tabular}




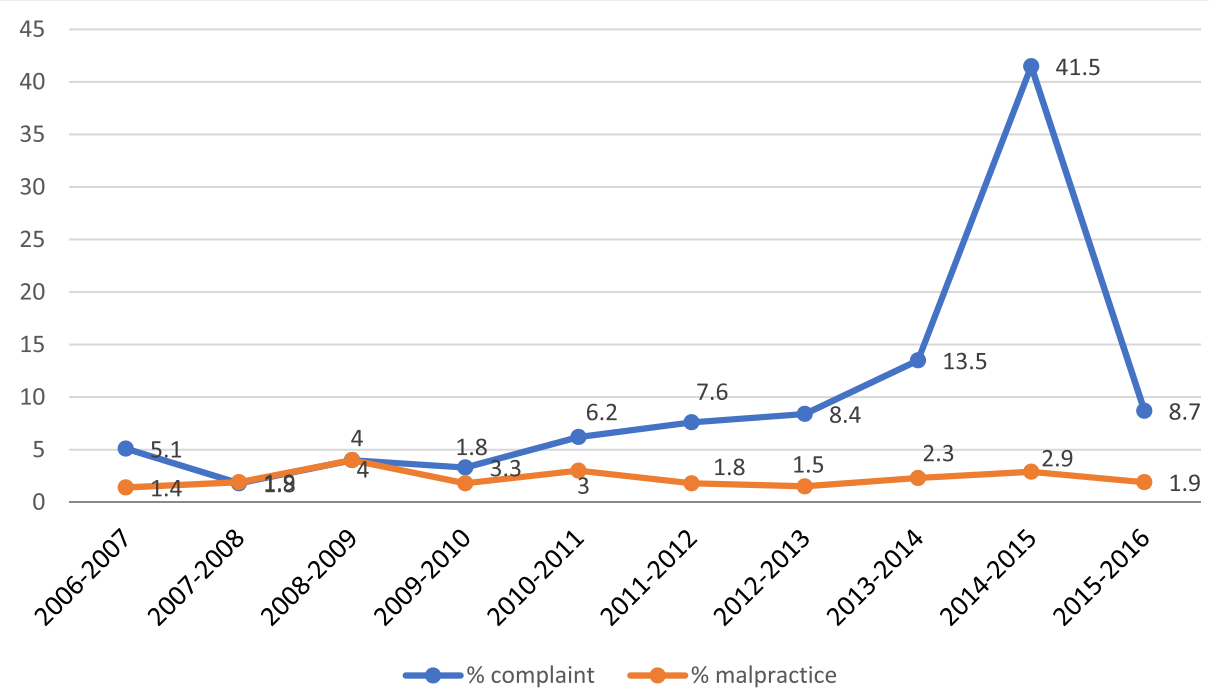

Fig. 3 Full Atonement for an individual in Iran is 2,310,000,000 Rials substitute 55,000\$ Dollar (based on 42000 Rials tariff), and calculated numbers in above table determined based on malpractice percentage of each physician cross the amount of atonement for an individual

According to the high ratio of cesarean section (CS) to normal vaginal delivery (NVD) and the high tendency to have children in Iran, "while the government has been working hard to control it but, it has not yet reached the desired result," and also, according to the dangers and complications of CS section, maximum malpractice payment belongs to gynecology for as much as 50,358,000 Rials which equaled to US $\$ 11,990$ and general surgery field sustained the minimum amount of malpractice payment which involved malpractice and complaint simultaneously with internists. Among subspecialty fields, the maximum amount of malpractices belonged to gastroenterology for as much as $38,808,000$ Rials which equaled to US\$9240, and the most important reason of which is diagnostic treatments as colonoscopy, endoscopy, and endoscopic retrograde cholangiopancreatography (ERCP).

\section{Conclusion}

Annual malpractice which reached a final decision from the beginning of 2006 to the end of 2016 varied from 0 to $5 \%$ generally, while the rate of the annual complaints which was registered in the forensic medicine organization in the same period varied between 0 and $45 \%$. Maximum malpractice payment belonged to gynecology for as much as 50,358,000 Rials which equals to US $\$ 11,990$ that involved malpractice and complaint simultaneously with internists.

The most prevalent cause of death in complaints was colonoscopy, endoscopy, and ERCP, followed by misdiagnosis. Also, the most prevalent cause of side effects in complaint cases was sepsis and infection after hospital admission in general (Table 2).

\section{Abbreviations}

CABG: Coronary artery bypass grafting; CS: Cesarean section; EMS: Emergency medical service; ERCP: Endoscopic retrograde cholangiopancreatography; GP: General practitioner; GI: Gastrointestinal; NVD: Normal vaginal delivery; PTE: Pulmonary thromboembolism

\section{Acknowledgements}

The present article was extracted from the thesis written by Pedram Keshavarz and was financially supported by Shiraz University of Medical Sciences (no. 13277).

The author of this study thanks the staff of Fars province general administration of Forensic Medicine for their kind cooperation in gathering data.

\section{Funding}

There is no funding resource for this study.

\section{Availability of data and materials}

The sources of data are available if needed.

\section{Authors' contributions}

Study concept and design was performed by PK and MD. Acquisition of data, analysis, statistical analysis interpretation of data, and drafting of the manuscript were done by PK, SG, and MZ. FM and AM gathered the data. PK and $M Z$ did critical revision of the manuscript for important intellectual content. Administrative, technical, and material support was by PK, and finally, study supervision was performed by MD and SG. All authors read and approved the final manuscript.

\section{Authors' information}

All authors contributed in this paper and final manuscript was approved by the authors. There is no conflict of interest for authors. Authors had no grant or funding source.

Ethics approval and consent to participate

All procedures performed in this study involving human participants were in accordance with the ethical standards of the institutional and/or national research committee and with the 1964 Helsinki Declaration and its later amendments or comparable ethical standards. For this type of study format, consent is not required.

Consent for publication

All authors and subjects have declared consent for publication of this study. 


\section{Competing interests}

The authors declare that they have no competing interests.

\section{Publisher's Note}

Springer Nature remains neutral with regard to jurisdictional claims in published maps and institutional affiliations.

\section{Author details}

${ }^{1}$ Student Research Committee, School of Medicine, Shiraz University of Medical Sciences, Shiraz, Iran. ${ }^{2}$ Hematology Research Center, Hematology and Medical Oncology Department, Shiraz University of Medical Sciences, Shiraz, Iran. ${ }^{3}$ Internal Medicine Department, Shiraz University of Medical Sciences, Shiraz, Iran. ${ }^{4}$ Legal Medicine Research Center, Legal Medicine Organization, Tehran, Iran. ${ }^{5}$ Internal Medicine Department, Namazee Hospital, P.O. Box: 7194835356, Zand Street, Shiraz, Iran.

Received: 27 December 2018 Accepted: 29 April 2019

Published online: 25 May 2019

\section{References}

Arhan M, Önal IK, Ödemis B, İbiş M, Şaşmaz N. Colonoscopy-induced ischemic colitis in a young patient with no risk factor. The American journal of gastroenterology. 2009 Jan;104(1):250

Beigi M, Asadi L, Valiani M, Mardani F. Evaluating different types of malpractices in midwifery that were referred to the forensic medicine commission and the medical council between 2006 and 2011 in Isfahan province, 2013. Iranian journal of nursing and midwifery research. 2015;20(4):426.

Büken E, Büken NÖ, Büken B. Obstetric and gynecologic malpractice in Turkey: incidence, impact, causes and prevention. Journal of clinical forensic medicine. 2004 Oct 1;11(5):233-47.

Casali MB, Mobilia F, Del Sordo S, Blandino A, Genovese U. The medica malpractice in Milan-Italy. A retrospective survey on 14 years of judicial autopsies. Forensic science international. 2014 Sep 1; 242:38-43.

Castro MF, Ferrara P, Guccio C, Lisi D (2018) Medical malpractice liability and physicians' behavior: experimental evidence. HEDG, c/o Department of Economics, University of York

Dyrbye $L$, Shanafelt T. A narrative review on burnout experienced by medical students and residents. Medical education. 2016 Jan;50(1):132-49.

Friele RD, Reitsma PM, De Jong JD. Complaint handling in healthcare: expectation gaps between physicians and the public; results of a survey study. BMC research notes. 2015 Dec;8(1):529.

Gaither TW, Copp HL. State appellant cases for testicular torsion: Case review from 1985 to 2015. Journal of pediatric urology. 2016 Oct 1;12(5):291-e1.

Hamilton DJ (2016) Scotland, the Caribbean and the Atlantic world 1750-1820

Jimenez-Corona ME, Ponce-de-Leon-Rosales S, Rangel-Frausto S, Mohar-Betancourt A. Epidemiology of medical complaints in Mexico: identifying a general profile. International Journal for Quality in Health Care. 2006 Mar 14;18(3):220-3.

Kermode-Scott B. US has most reports of medical errors. BMJ. Publishing Group; 2005.

King A, Crewe I. The blunders of our governments: Oneworld Publications; 2014

Li Y, Gao D, Tu M, Luo YZ, Deng ZH. Investigation of pathology malpractice claims in China from 2002-2015. Journal of forensic and legal medicine. 2017 May 1: 48:30-4.

Madea B, Preuß J. Medical malpractice as reflected by the forensic evaluation of 4450 autopsies. Forensic science international. 2009 Sep 10;190(1-3):58-66.

Mossialos E, Wenzl M, Osborn R, Sarnak D. 2015 international profiles of health care systems. Canadian Agency for Drugs and Technologies in Health; 2016 Jan.

Nakanishi T. Disclosing unavoidable causes of adverse events improves patients feelings towards doctors. The Tohoku journal of experimental medicine. 2014:234(2):161-8

Obama B. United States health care reform: progress to date and next steps. Jama. 2016 Aug 2;316(5):525-32.

Oshel RE, Levitt P (2016) The detection, analysis, and significance of physician clustering in medical malpractice lawsuit payouts

Popescu GH. Increased medical malpractice expenditures as a main determinant of growth in health care spending. American Journal of Medical Research. 2015; 2(1):80-6.

Schaffer AC, Jena AB, Seabury SA, Singh H, Chalasani V, Kachalia A. Rates and characteristics of paid malpractice claims among US physicians by specialty, 1992-2014. JAMA internal medicine. 2017 May 1;177(5):710-8.

Studdert DM, Mello MM, Gawande AA, Gandhi TK, Kachalia A, Yoon C, Puopolo AL, Brennan TA. Claims, errors, and compensation payments in medical malpractice litigation. New England journal of medicine. 2006 May 11; 354(19):2024-33.

Traina F. Medical malpractice: the experience in Italy. Clinical orthopaedics and related research. 2009 Feb 1;467(2):434-42.

Velsor S, Rogers R, Law T (2018) Differentiating factitious psychological presentations from malingering: implications for forensic practice

Zengin S, Al B, Yavuz E, Kursunköseler G, Guzel R, Sabak M, Yildirim C. Analysis of complaints lodged by patients attending a university hospital: a 4-year analysis. Journal of forensic and legal medicine. 2014 Feb 1; 22:121-4.

\section{Submit your manuscript to a SpringerOpen ${ }^{\circ}$ journal and benefit from:}

- Convenient online submission

- Rigorous peer review

- Open access: articles freely available online

- High visibility within the field

- Retaining the copyright to your article

Submit your next manuscript at $\boldsymbol{\nabla}$ springeropen.com 